\title{
Birds fly in the face of 'green' farming incentive scheme
}

\section{John Whitfield, London}

The effectiveness of schemes that seek to promote biodiversity by paying farmers to cut back on intensive agriculture could be called into question by some research findings from Holland.

The incentive programmes, which already cost the European Union 1.7 billion euros (US $\$ 1.5$ billion) each year and are rapidly expanding in scope, are partly motivated by the desire of European governments to subsidize farming without promoting the overproduction of food. But the programmes have been publicly justified by claims that they will help to restore ecological biodiversity on farmland.

In this issue of Nature, David Kleijn and colleagues at Wageningen University report results from one of the first schemes of this kind, operated by the Dutch government since 1981. They find that it has failed to significantly increase biodiversity in fields where farmers were paid to delay mowing or grazing, and to reduce the amount of fertilizer they used (see page 723 ).

The study did not examine how the total biodiversity in the region had changed over time, however. And EU officials and some conservationists are confident that the more sophisticated programmes now being implemented will increase biodiversity.

But many ecologists claim that such programmes have not been properly evaluated. "There are far too few studies of this kind," says population biologist Arie van Noordwijk of the Netherlands Institute of Ecology's Centre for Terrestrial Ecology in Heteren. "We have hardly any good data on the effectiveness of these programmes, and vast amounts of money are spent on them Europe-wide."

Kleijn's study counted species and numbers of plants, birds, bees and hoverflies in 78 fields last summer. Only bee and hoverfly

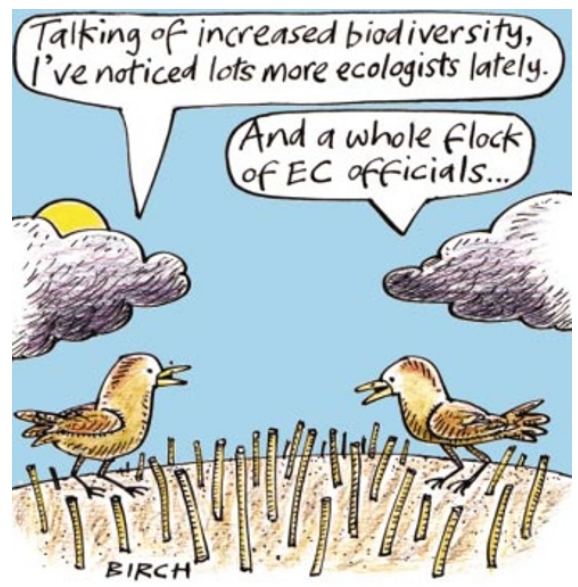

\section{Plans to centralize biology research set for rough ride}

Dutch dilemma: the blackamong birds that have not benefited from a scheme to limit intensive agriculture. tailed godwit (left) is

\section{David Cyranoski, Tokyo}

A special summit meeting in Tokyo next week is expected to be dominated by arguments over whether Japan needs a new life-sciences research agency akin to the US National Institutes of Health (NIH).

The Japan Association of

Bioindustries Executives (JABEX), one of the groups hosting the meeting, plans to use it to publicly unveil an ambitious plan to streamline support mechanisms for life-sciences research in Japan. Currently, such support comes from several different sources, including the health, education and economics ministries.

Although details of the proposal remain sketchy, it is known to involve the creation of a powerful biomedical research agency with responsibility for both basic and clinical research. The new body would seek to bolster Japan's flagging clinical-research efforts and encourage more rapid commercialization of research findings.

But some Japanese researchers are diversity increased under the scheme. Birds actually seemed to prefer intensively farmed fields, possibly because reductions in fertilizer use lead to smaller invertebrate populations and so less food.

Kleijn thinks the study area is representative of intensively managed farmland across northern Europe, but admits that the effectiveness of such schemes in hill-farm regions, for example, may be quite different.

According to Carlos Martin-Novella, an official at the European Commission's Development and Environment Unit in Brussels, the European Union has already adjusted its subsidy schemes to increase their effectiveness, and made arrangements to monitor them. For example, the commission's biodiversity action plan, published earlier this year, requires member states to evaluate their agri-environment schemes. The new research "fits very well into this commitment", says Martin-Novella.

David Gibbons, head of conservation science at the Royal Society for the Protection of Birds, a British conservation group, says that recent environmental subsidy schemes are designed with more scientific input than the Dutch study. Britain's Arable Stewardship project, for example, which aims to restore farmland bird populations, expressly targets individual species. It will require farmers to leave stubble - an important food source for birds - in fields over the winter, instead of digging it up to plant crops such as winter wheat. The scheme is to be launched in 2002 after a three-year pilot study. "I'd be shocked if we don't see real benefits over the next 5-10 years," says Gibbons. worried that such a centralized body might stifle their independence. They are also unhappy that JABEX has taken its proposal directly to the government's Council for Science and Technology Policy (CSTP), instead of asking them first.

"They are approaching the CSTP without first consulting with researchers, and this makes me uneasy," says Takeshi Gojobori, head of the bioinformatics unit at the National Institute of Genetics in Mishima.

Osamu Chisaki, secretary of JABEX, says the CSTP would play a central role in implementing the plan.

The idea has already come under fire from officials at the education ministry, which currently supports most basic biology research. They claim that an NIHtype agency wouldn't work in Japan because it would become too bureaucratic. Research-policy decisions would become top-down and basic research would suffer, predicts one University of Tokyo researcher.

The summit, to be held on 22 October, will bring academics, such as Nobel laureate Susumu Tonegawa of the Massachusetts Institute of Technology, together with politicians, government officials and industry representatives. They will discuss the possibilities for restructuring biomedical research in Japan in line with the government reform efforts of Prime Minister Junichiro Koizumi, who will afterwards attend a reception. 